\title{
Risk of infection in patients with spondyloarthritis and ankylosing spondylitis receiving antitumor necrosis factor therapy: A meta-analysis of randomized controlled trials
}

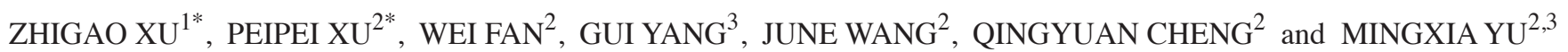 \\ ${ }^{1}$ Department of Pathology; ${ }^{2}$ Center for Gene Diagnosis; ${ }^{3}$ Department of Clinical Laboratory, \\ Zhongnan Hospital of Wuhan University, Wuhan, Hubei 430071, P.R. China
}

Received September 30, 2016; Accepted June 2, 2017

DOI: $10.3892 / \mathrm{etm} .2017 .5003$

\begin{abstract}
Antitumor necrosis factor (TNF) agents have been widely used for the treatment of spondyloarthritis (SpA) and ankylosing spondylitis (AS). However, these agents may increase the risk of infection due to suppressing the immune response. The present meta-analysis was performed to systematically investigate the risk of overall infection, serious infection and tuberculosis in patients with SpA and AS treated with anti-TNF agents. Medline, Embase and the Cochrane library were searched for randomized controlled trials (RCTs) published between January 1998 and December 2015 about infection in patients with $\mathrm{SpA}$ receiving anti-TNF therapy. Data were pooled to obtain relative risks (RRs) along with their $95 \%$ confidence intervals (CIs). A total of 25 RCTs investigating SpA, including 12 investigating AS specifically, were eligible for the meta-analysis. Similar risks of overall infection were reported in patients with SpA (RR, 1.03; 95\% CI, 0.92-1.15) and AS (RR, 1.06; 95\% CI, 0.91-1.24) treated with anti-TNF agents. The RR of serious infection for patients with SpA or AS receiving anti-TNF therapy compared with a placebo was 1.27 (95\% CI, 0.67-2.38) and 1.57 (95\% CI, 0.63-3.91), respectively. In addition, 4 RCTs with outcomes of tuberculosis in patients with SpA receiving anti-TNF agents were identified, all in infliximab-treated patients ( $R R, 2.52$; 95\% CI, 0.53-12.09). However, due to the limited number of RCTs, this finding should be interpreted with caution. The present meta-analysis did not find any significantly increased risk of infection associated with anti-TNF therapy in patients with $\mathrm{SpA}$ or AS. However, due to short duration of follow-up in
\end{abstract}

Correspondence to: Professor Mingxia Yu, Department of Clinical Laboratory, Zhongnan Hospital of Wuhan University, 169 Donghu Road, Wuhan, Hubei 430071, P.R. China

E-mail: dewrosy520@163.com

*Contributed equally

Key words: antitumor necrosis factor agents, spondyloarthritis, ankylosing spondylitis, infection, meta-analysis the RCTs and the rarity of serious infections and tuberculosis, patients treated with anti-TNF agents still should be closely monitored in clinical practice.

\section{Introduction}

Spondyloarthritis (SpA) is a group of chronic inflammatory rheumatic diseases with pathophysiological, clinical, radiological and genetic features of inflammatory back pain with or without peripheral arthritis, combined with certain features of extra-articular manifestations. Diseases in this category include ankylosing spondylitis (AS), reactive arthritis, psoriatic arthritis, arthropathy of inflammatory bowel disease, undifferentiated $\mathrm{SpA}$ and juvenile chronic arthritis (1-3). As $\mathrm{SpA}$ diseases progress they can develop into AS, which is the most severe and common subtype of SpA. The primary clinical symptoms of AS include pain, joint stiffness and loss of spinal mobility, which can result in severe impairment of function and a decrease in the patient's quality of life $(4,5)$.

The primary treatments for patients with SpA include general drug treatments accompanied with physiotherapy. However, short-term corticosteroids, conventional non-steroidal anti-inflammatory drugs and disease modifying anti-rheumatic drugs, including methotrexate and sulfasalazine, have not proved to be particularly effective for the treatment of SpA while causing a high incidence of side effects (6-8). Tumor necrosis factor (TNF)- $\alpha$, a pleiotropic cytokine that is produced during the inflammatory response, serves an important role in the pathogenesis of numerous chronic inflammatory and rheumatic diseases (9). The therapies used for the treatment of SpA have undergone a drastic revision since the development of anti-TNF agents, which inhibit and prevent TNF- $\alpha$ from promoting inflammation, and therefore are beneficial for alleviating the symptoms of SpA (10)

While anti-TNF biologics improve the function and quality of life of patients with SpA, suppressing the immune system makes patients more susceptible to infections. This is the most adverse effect of anti-TNF agent therapy, and has been demonstrated to be significantly higher in patients with SpA, particularly AS, treated with anti-TNF agents compared with those receiving non-biological treatments (11). Serious 
infection, whilst rare, is severe and thus the inhibitory effects of anti-TNF therapy on the immune response are important. Considering that anti-TNF agents usually require long-term application in patients with SpA and AS (10,12), a meta-analysis was performed to investigate whether the risk of serious infection, including tuberculosis, is increased in patients with $\mathrm{SpA}$ or AS treated with anti-TNF agents. In addition, the overall infection rate in patients with SpA or AS was investigated.

\section{Materials and methods}

Data sources and search strategy. The design of the present meta-analysis was prepared in accordance with the preferred reporting items for systematic reviews and meta-analyses statement (13). Medline (www.ncbi.nlm.nih.gov), Embase (www.embase.com) and the Cochrane Library (www .cochranelibrary.com) were searched for publications from January 1998 to December 2015 with the following terms: 'Spondyloarthritis', 'ankylosing spondylitis', 'psoriatic arthritis' or 'reactive arthritis' combined with 'biologics', 'anti-TNF agent' or the names of specific biologic agents, including 'etanercept', 'infliximab', 'adalimumab', 'certolizumab pegol', 'golimumab', and combined with 'adverse reaction' and 'infection'. Searches were restricted to English language publications and studies in humans. The search was supplemented by manual searches of the proceedings of the American College of Rheumatology (www.rheumatology.org) and the European League Against Rheumatism (www.eular .org). Meanwhile, to identify all relevant articles, the reference lists from associated reviews and meta-analyses were also searched manually.

Study selection. Randomized controlled trials (RCTs) comparing anti-TNF agents with placebos (or other medications), alone or in combination, in patients with SpA were identified. The inclusion and exclusion criteria were as described below. i) Study design: The study must be an RCT; for trials with a cross-over design, a double-blind period followed by an open-label period was eligible for inclusion, while studies with a Jadad score $<3$ were excluded. ii) Participants: The enrolled patients must fulfill the assessment of SpA criteria for peripheral $\mathrm{SpA}$ and $\mathrm{SpA}$ in general (14), and patients who were suffering from chronic infections at the beginning of experiments were excluded. iii) Intervention: Studies comparing treatment with infliximab, etanercept, adalimumab, golimumab and certolizumab pegol, either alone or in combination with other medications, against a control group were included; trials using a single infusion or injection of an anti-TNF agent were excluded. Additionally, the duration of the placebo-controlled phases across trials were limited to short term. iv) Endpoints: All included articles must demonstrate the outcomes associated with infection. Studies were independently screened and selected by two investigators, and discrepancies were resolved through discussion.

Data extraction and quality assessment. Using a preformed form, data were extracted by two independent investigators with any discrepancies resolved by discussion. In addition to general information, including the first author, publication year, study design, underlying disease, interventions, study duration, sample size and other specific circumstances, the present study focused on extracting outcomes of the events, including the occurrence of overall infection, serious infection and tuberculosis. For the studies that included a double-blind period and an open-labeled period, only the result of the double-blind period was extracted. Notably, in one trial of etanercept with administration of $25 \mathrm{mg}$ twice a week or $50 \mathrm{mg}$ once a week, the decision was made to present the combined results as these regimens were demonstrated to be equivalent in terms of benefit and safety (15). Selected studies were critically appraised for quality based on the Jadad scale (16).

Statistical analysis. Extracted data were analyzed using the Mantel-Haenszel method with Review Manager software (version 5.2, The Cochrane Collaboration, Copenhagen, Denmark). The $\mathrm{Q}$ test and $\mathrm{I}^{2}$ statistics were used to evaluate the heterogeneity of the RCTs in accordance with the Cochrane Handbook (17). An $\mathrm{I}^{2}$ value of $>50 \%$ accompanied with a P-value $<0.05$ for the $\mathrm{Q}$ test was determined to indicate the presence of significant heterogeneity. When there was no significant heterogeneity, a fixed effects model was used; otherwise a random effects model was applied. Forest plots were constructed to display relative risk (RR) estimates and 95\% confidence intervals (CIs). Funnel plots were assessed for evidence of asymmetry, followed by possible publication bias or other small study effects. Subgroup analysis was performed to explore potential differences by stratifying different anti-TNF agents in patients with SpA and AS. For sparse data on serious infection, due to null values in either the intervention or control arms in several trials, either a crude analysis was performed by combining study results, or the studies were excluded, according to the methodological description by Bradburn et al (18). Sensitivity analysis was also performed to inspect the robustness of the data using Stata software (version 12.0, StataCorp LP, College Station, TX, USA).

\section{Results}

Study selection and characteristics. A flow diagram depicting the process of searching and selecting RCTs was presented in Fig. 1. A total of 1,621 unique RCTs were obtained after removing duplicates from the initial search that identified 1,744 studies. Of these studies, 1,526 were excluded through reading the title and abstract. Via a detailed full-text review of the remaining 95 studies, 26 articles were retrieved for evaluation. With 1 study eliminated due to a Jaded score below the cutoff level of 3 (19), ultimately 25 articles were eligible for inclusion in the analysis $(2,15,20-42)$. Notably, 2 trials $(29,42)$ that were not double-blind were included in the primary analysis, though the quality of their Jadad scores was not particularly high. Among the 25 articles eligible for analysis, 12 studies were investigating patients with AS.

Table I listed the general characteristics of the 25 articles included in the present study. With regards to the anti-TNF agents utilized, 9 trials used etanercept, 7 used infliximab, 7 used adalimumab and 2 used golimumab. No RCTs investigating certolizumab pegol were eligible for analysis due to 


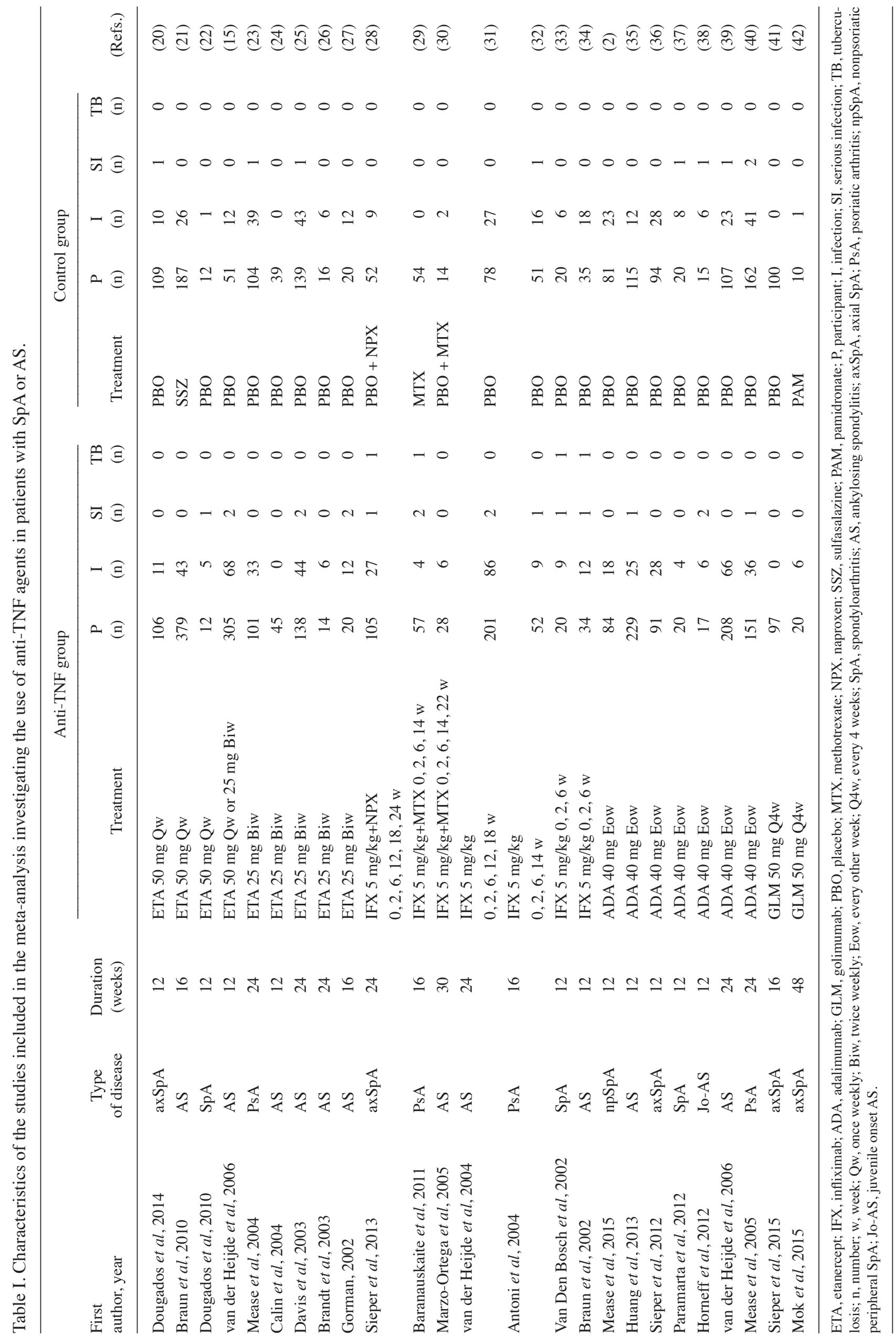


their inadequate presentation of infection outcomes (43-45). The quality of the eligible studies met the required standards, with a mean Jadad score of $5.80 \pm 1.04$. The duration of placebo-controlled phases across trials ranged from 12 to 48 weeks. In addition, the dosages of the biologics used in these RCTs met US Food and Drug Administration standards.

Overall infection rate of patients with $S p A$ or AS receiving anti-TNF agents vs. a placebo. In the 25 studies identified, $564 / 2,534$ patients with $\mathrm{SpA}(22.3 \%)$ who received anti-TNF agents and 369/1,685 patients with SpA (21.9\%) who received a placebo experienced an infection. Thus, no significant difference was identified in the infection rate between patients with SpA treated with anti-TNF agents compared with those who received a placebo (RR, 1.03; 95\% CI, 0.92-1.15; Fig. 2). The risk of overall infection was then stratified by the type of anti-TNF agent. No significant differences were observed in the infection rate between patients with SpA treated with a specific anti-TNF agent compared with a placebo. The individual results were as follows: Etanercept (RR, 0.97; 95\% CI, 0.81-1.16); infliximab (RR, 1.11; 95\% CI, 0.88-1.40); adalimumab (RR, 1.02; 95\% CI, 0.84-1.24); and golimumab (RR, 3.00; 95\% CI, 0.42-21.65) (Fig. 2).

Among the RCTs evaluated, 12 investigated patients with AS. The incidence of infection in these studies was similar between the groups treated with anti-TNF agents (374/1,618 patients; $23.1 \%$ ) and the control (187/816 patients; $22.9 \%)$. There was no significant difference in the overall rate of infection between these groups (RR, 1.06; 95\% CI, 0.91-1.24; Fig. 3). Subgroup analysis by the type of anti-TNF agent used also revealed no significant differences, with the following individual results: Etanercept (RR, 0.95; 95\% CI, 0.77-1.19); infliximab (RR, 1.08; 95\% CI, 0.81-1.44); adalimumab (RR, 1.27; 95\% CI, 0.92-1.24); and golimumab (RR, 3.00; 95\% CI, 0.42-21.65) (Fig. 3).

Serious infection rate of patients with $S p A$ or AS receiving anti-TNF agents vs. a placebo. A total of 19/2,534 patients with SpA $(0.75 \%)$ treated with anti-TNF agents had a serious infection compared with $9 / 1,685$ patients $(0.53 \%)$ who received a placebo. By pooling the data crudely, the relative risk of serious infection in patients with SpA treated with anti-TNF agents compared with the control group was 1.40 (95\% CI, 0.64-3.10). After discarding the null studies, 17 RCTs were evaluated. Compared with patients treated with a placebo, patients receiving anti-TNF agents did not have a significantly increased risk of serious infection (RR, 1.27; 95\% CI, 0.67-2.38; Fig. 4). The subgroup analysis that stratified the studies based on the anti-TNF agent used did not identify any significant heterogeneity compared with the control group either. The results were as follows: Etanercept (RR, 1.33; 95\% CI, 0.46-3.85); infliximab (RR, 2.27; 95\% CI, 0.68-7.54); and adalimumab (RR, 0.67; 95\% CI, 0.22-2.06) (Fig. 4).

Similarly, in the 12 RCTs investigating patients with AS, $12 / 1,618$ patients $(0.74 \%)$ who received anti-TNF agent therapy experienced serious infection compared with $3 / 816$ patients $(0.37 \%)$ in the control group. This crude pooled result demonstrated that anti-TNF agents did not significantly increase the risk of serious infection in patients with AS (RR, 2.02; 95\%

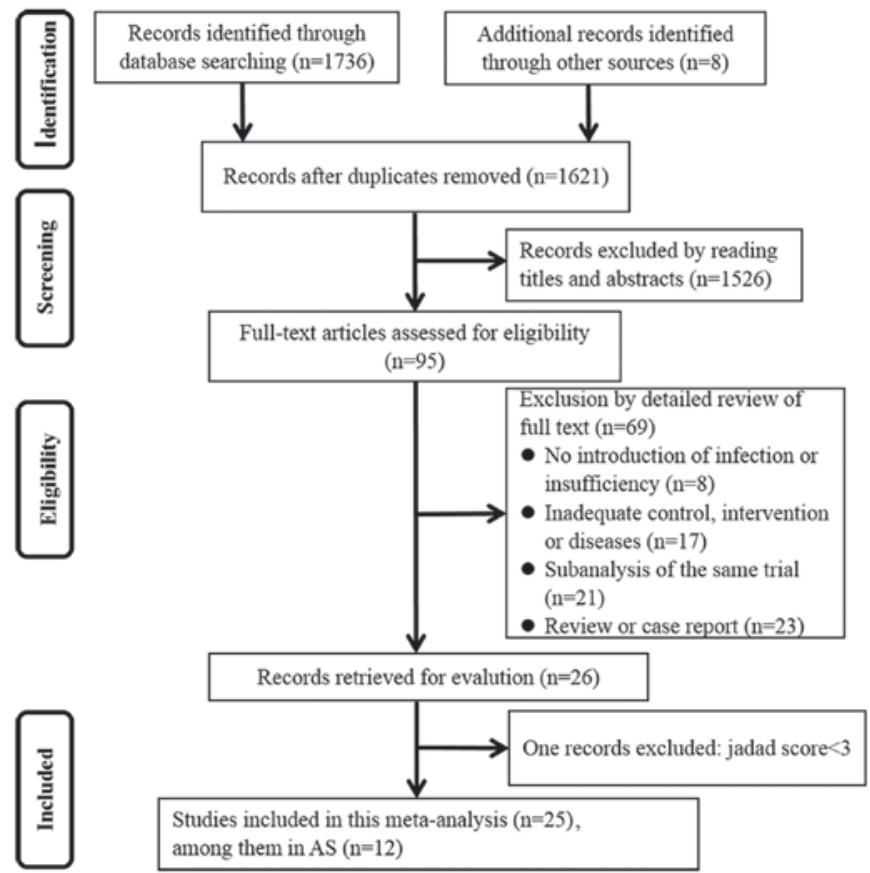

Figure 1. Flow diagram depicting the process of searching and selecting randomized controlled trials for the meta-analysis. AS, ankylosing spondylitis.

CI, 0.57-7.13). After the 4 null RCTs abandoned, 8 studies were eligible for further analysis. The meta-analysis demonstrated that anti-TNF agents resulted in a 1.57-fold higher risk of serious infection in patient with AS compared with the control group (RR, 1.57; 95\% CI, 0.63-3.91; Fig. 5). Individually, etanercept resulted in a 2.23-fold higher likelihood of serious infection (RR, 2.23; 95\% CI, 0.49-10.10) and infliximab in a 2.42-fold higher likelihood (RR, 2.42; 95\%, CI, 0.27-21.24), while adalimumab reduced the risk of serious infection (RR, 0.87; 95\% CI, 0.21-3.61) (Fig. 5). However, none of these results were statistically significant.

Rate of tuberculosis infection in patients with $S p A$ receiving anti-TNF agents vs. a placebo. In the $25 \mathrm{RCTs}$ included in the present study, only 4 studies revealed incidences of tuberculosis, which all emerged in infliximab-treated patients with SpA (Fig. 6). Thus, infliximab treatment resulted in a 2.42-fold higher likelihood of tuberculosis in patients with SpA compared with the control group (RR, 2.42; 95\% CI, 0.40-14.70); however, this result was not significant (Fig. 6). In addition, due to the limited number of RCTs, this finding should be interpreted with caution.

Publication bias. Funnel plots were produced to assess the publication bias of the included studies. The shape of funnel plots revealed no obvious asymmetry (Fig. 7), indicating that there was no publication bias for the overall and serious infection outcomes identified in patients with SpA or AS.

Sensitivity analysis. Sensitivity analysis was performed by omitting individual studies to evaluate the robustness of the data. The results revealed that the RR was not influenced meaningfully in each model (Fig. 8). Notably, the 2 studies that 


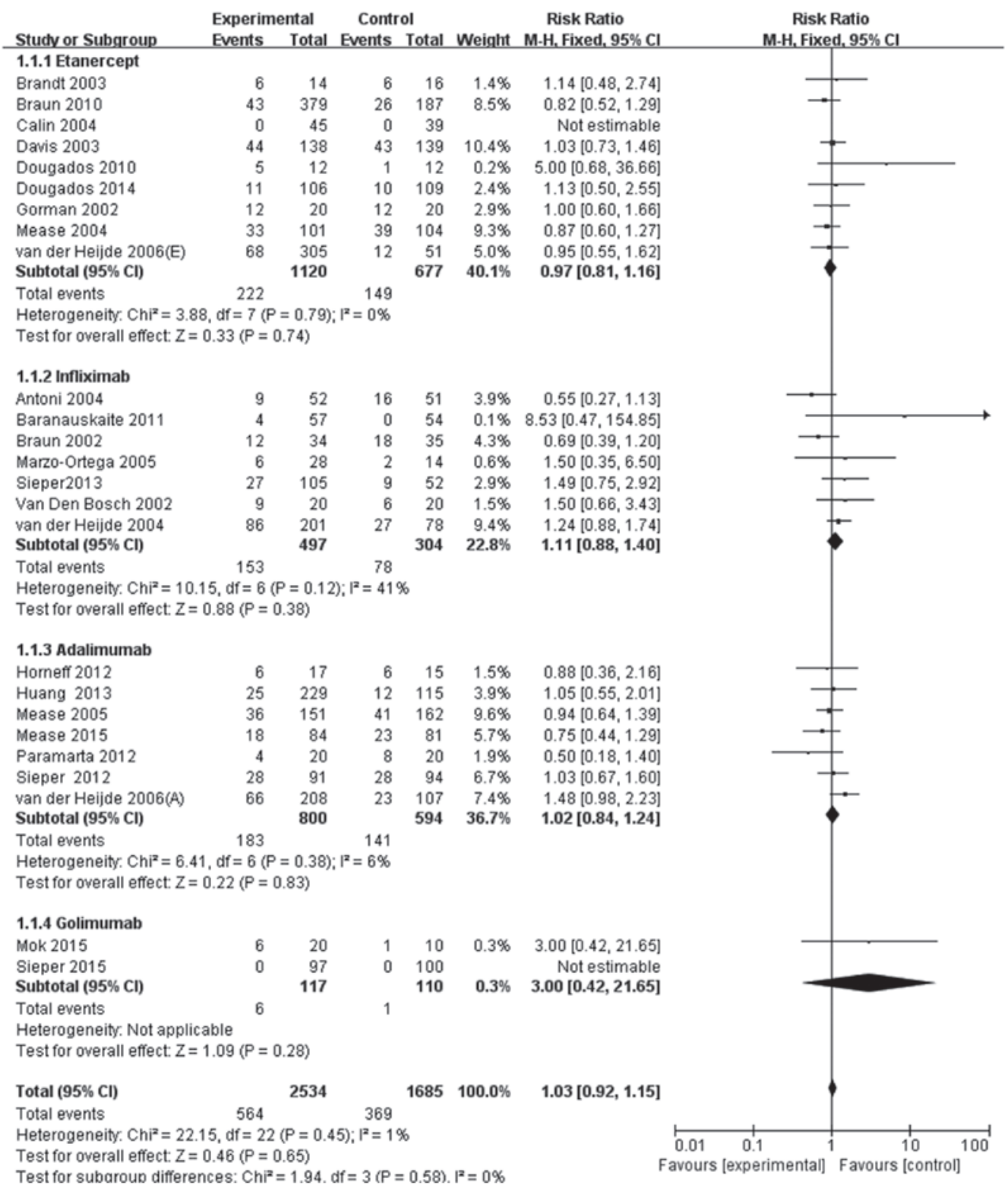

Figure 2. Meta-analysis of overall infection risk in patients with spondyloarthritis treated with anti-TNF agents. M-H, Mantel-Haenszel method; CI, confidence interval.

were not double-blinded trials did not influence the robustness of the present study.

\section{Discussion}

Presently, there are five anti-TNF agents available for the treatment of SpA, which are divided into three categories $(46,47)$. One category includes etanercept, a soluble receptor of the p75 TNF receptor/Fc fusion protein. Another category includes the monoclonal antibodies infliximab, adalimumab and golimumab. Infliximab is composed of a murine variable region and human constant region, while adalimumab and golimumab are human antibodies. The last category includes certolizumab pegol, a recombinant humanized antibody of the Fab region conjugated to polyethylene glycol. The use of these drugs is a double-edged sword, as suppressing the immune response improved the symptoms of patients with SpA but also increased the risk of infection (48-52). To the best of our knowledge, the present meta-analysis was the first and largest review examining the risk of infection in patients with $\mathrm{SpA}$ treated with anti-TNF agents in RCTs. In AS, a meta-analysis was published to assess serious infection in patients receiving TNF blockers in 2010 (53). Considering more single studies arising published after $2010(21,35,38)$ and the absence of data identifying respective risk of different anti-TNF agents in the previous meta-analysis, an updated meta-analysis regarding serious infection with use of TNF inhibitors for AS was performed in the present study.

The results of the present study revealed that there was no increased risk of overall infection with the short-term use of anti-TNF agents for patients with SpA or AS. Among the studies identified, the majority of reported infections were minor, particularly upper respiratory tract infections. With regard to the risk of serious infection, the crude pooled result did not find an increased risk in patients with SpA or AS treated with anti-TNF agents. For the risk of serious infection in patients 


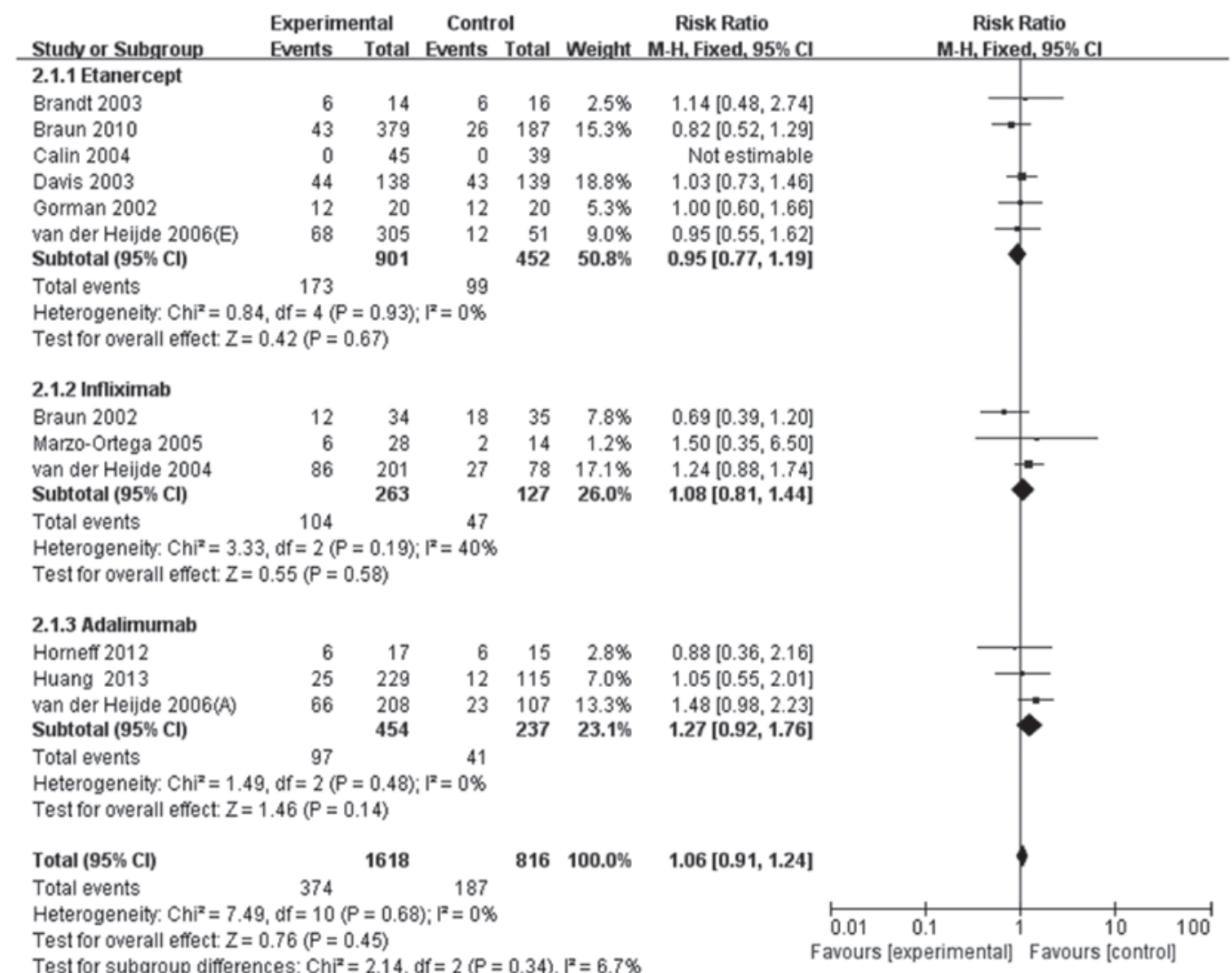

Figure 3. Meta-analysis of overall infection risk in patients with ankylosing spondylitis treated with anti-TNF agents. M-H, Mantel-Haenszel method; CI, confidence interval.

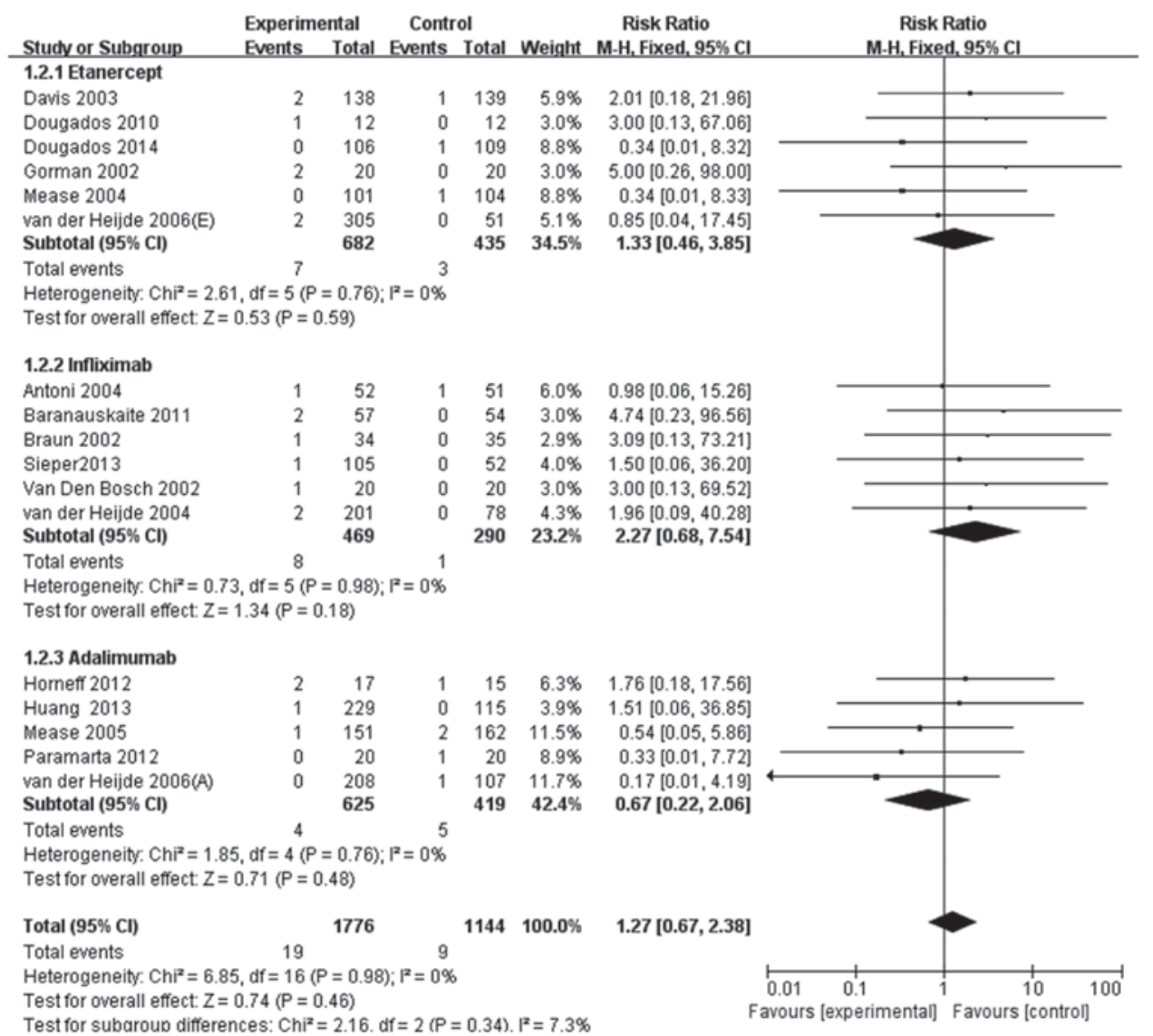

Figure 4. Meta-analysis of serious infection risk in patients with spondyloarthritis treated with anti-TNF agents. M-H, Mantel-Haenszel method; CI, confidence interval. 


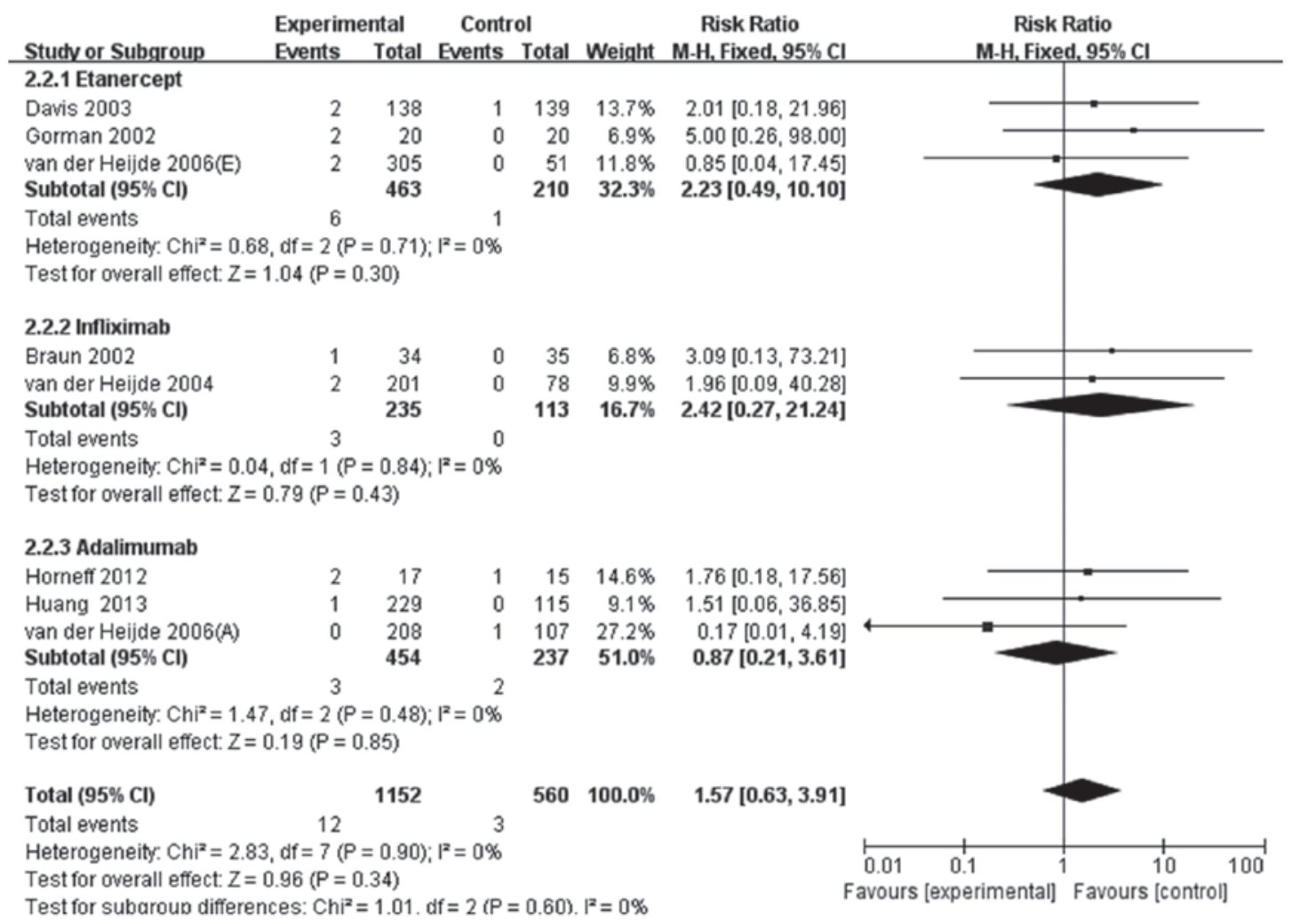

Figure 5. Meta-analysis of serious infection risk in patients with ankylosing spondylitis treated with anti-TNF agents. M-H, Mantel-Haenszel method; CI, confidence interval.

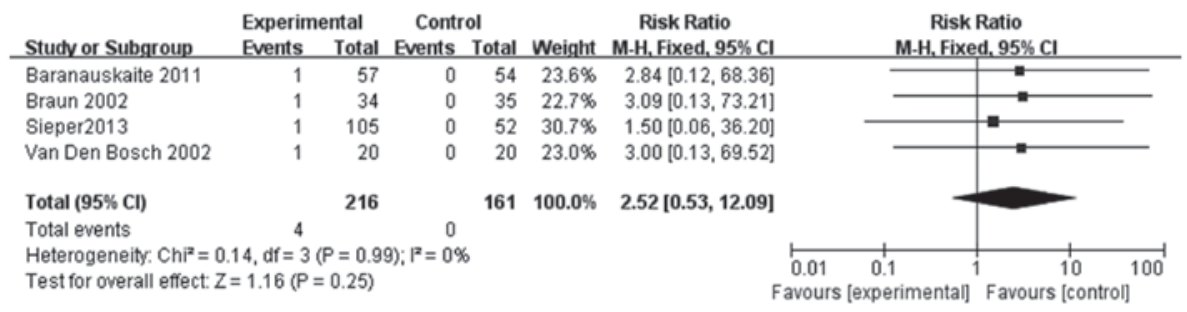

Figure 6. Meta-analysis of tuberculosis risk in patients with SpA treated with infliximab. M-H, Mantel-Haenszel method; CI, confidence interval.

with AS, the result of the present study was in accordance with the previous meta-analysis (53). However, compared with the prior meta-analysis, the present study had certain advantages. Firstly, the estimates were based on the pooling of 12 RCTs with an overall population of 2,434 participants compared with the prior study's sample size of 1,496 patients. With the large number of patients and similar results to the previous meta-analysis, it was unlikely that new individual RCTs would affect the conclusion of the present analysis. In addition, the present study brought golimumab into the meta-analysis and performed a subgroup analysis to explore the individual risk of infection from each anti-TNF agent. Furthermore, since SpA may develop into AS, in the meta-analysis, we didn't simply limit to the disease of AS and severity of infection, which could lead to a more comprehensive understanding and comparison as diseases progresses. Overall, the present study provided further support to the existing observational data, and was an updated and extended meta-analysis with detailed outcomes for infection.
On account of its seriousness and infectivity, tuberculosis was also an outcome that the present study investigated in patients with SpA treated with anti-TNF agents. In the analysis conducted in the current study, only 4 incidences of tuberculosis were detected in anti-TNF agent-treated patients with SpA, with the anti-TNF agent being infliximab in all cases. Certain previous studies have demonstrated that the incidence of tuberculosis is 3-4 times higher in patients with $\mathrm{SpA}$ receiving monoclonal antibody anti-TNF agents compared with those receiving etanercept $(54,55)$, which may be associated with the different mechanisms of tuberculosis infection. Saliu et al (56) reported that adalimumab and infliximab reduced the proportion of tuberculosis-responsive cluster of differentiation $(\mathrm{CD}) 69^{+} \mathrm{CD} 4$ cells by $50-70 \%$ and suppressed antigen-induced interferon $\gamma$ production in an in vitro intracellular infection model; however, etanercept had no significant effect. A Markov model performed by Wallis (57) revealed that infliximab-associated tuberculosis occurred within a very short time after taking the medicine (12-21 weeks), whereas 

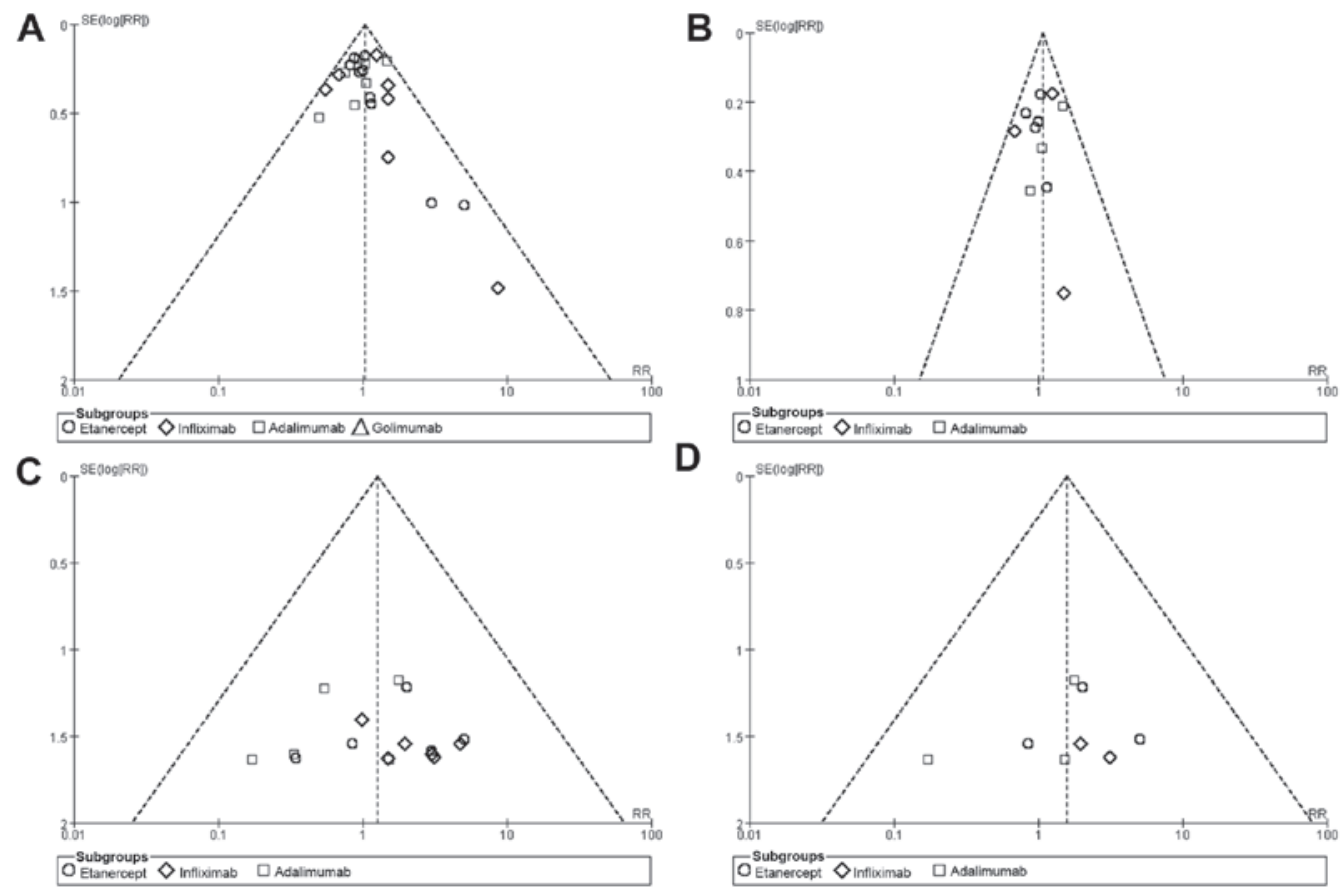

Figure 7. Funnel plots for publication bias of the studies included in the present meta-analysis. Funnel plots for overall infection risk associated with anti-TNF agents in patients with (A) SpA and (B) AS. Funnel plots for serious infection risk associated with anti-TNF agents in patients with (C) SpA and (D) AS. SpA, spondyloarthritis; AS, ankylosing spondylitis; SE, standard error; RR, relative risk.

A

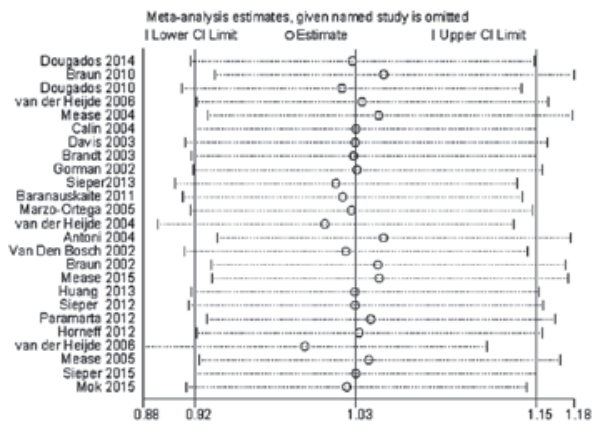

C

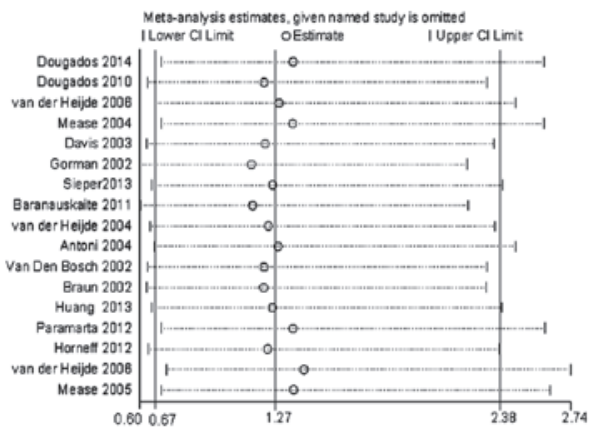

B

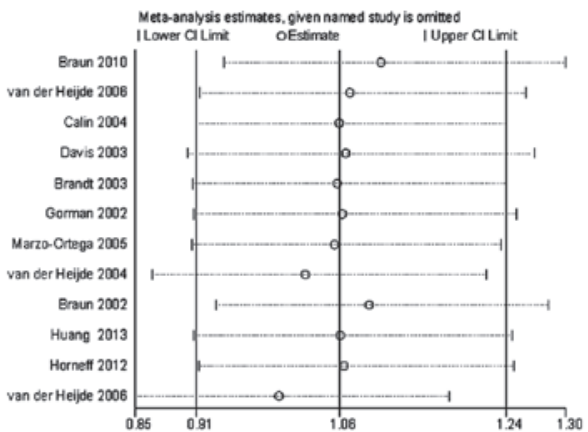

D

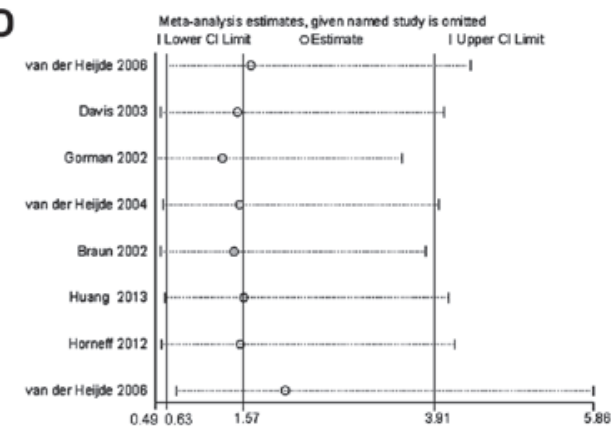

Figure 8. Sensitivity analysis. Sensitivity analysis was performed for overall infection associated with anti-TNF agents in patients with (A) SpA and (B) AS . Sensitivity analysis was also performed for serious infection associated with anti-TNF agents in patients with (C) SpA and (D) AS. SpA, spondyloarthritis; AS, ankylosing spondylitis; CI, confidence interval.

infection onset was 3-5 times later with etanecept. In addition, the risk of latent tuberculosis recurrence after infliximab was 12.1 times higher compared with etanecept (57). These results indicated that anti-TNF agents should be carefully selected and that tuberculosis should be screened for in a timely manner in the clinical practice of patients with SpA.
The present analysis had several limitations. The study search was limited to papers published in English, which may have excluded other relevant non-English language studies and affected the results. However, all large RCTs were included, so the exclusion of several small trials should not have altered the results. In addition, no publication bias was identified for 
any condition. Another limitation was that serious infection was determined according to each RCTs definition, which would increase heterogeneity to a certain extent. However, the sensitivity analysis performed would have minimized the role of such heterogeneity. In addition, due to the rarity of serious infection, and the short duration of treatment and follow-up, the present study did not assess the risk of serious infection stratified by follow-up time.

In conclusion, the results of the present meta-analysis suggest that there is not a significantly increased risk of infection in patients with SpA or AS receiving anti-TNF agent therapy. However, since anti-TNF agents typically need to be used for a long period of time, even lifelong, in patients with SpA, particularly AS, more long-term follow-up studies are required to confirm the findings of the present study, in addition to exploring the potential occurrence of tuberculosis.

\section{Acknowledgements}

The present study was supported by the National Natural Science Funds (grant nos. 81472033 and 30901308), the National Science Foundation of Hubei Province (grant nos. 2013CFB233 and 2013CFB235), the Scientific and Technological Project of Wuhan City (grant no. 2014060101010045), and the Hubei Province Health and Family Planning Scientific Research Project (grant no. WJ2015Q021).

\section{References}

1. Dougados M and Baeten D: Spondyloarthritis. Lancet 377: 2127-2137, 2011

2. Mease P, Sieper J, Van den Bosch F, Rahman P, Karunaratne PM and Pangan AL: Randomized controlled trial of adalimumab in patients with nonpsoriatic peripheral spondyloarthritis. Arthritis Rheumatol 67: 914-923, 2015.

3. Smolen JS, Braun J, Dougados M, Emery P, Fitzgerald O, Helliwell P, Kavanaugh A, Kvien TK, Landewé R, Luger T, et al Treating spondyloarthritis, including ankylosing spondylitis and psoriatic arthritis, to target: Recommendations of an international task force. Ann Rheum Dis 73: 6-16, 2014.

4. Braun J and Sieper J: Ankylosing spondylitis. Lancet 369: 1379-1390, 2007.

5. Davis JC, van der Heijde D, Dougados M and Woolley JM: Reductions in health-related quality of life in patients with ankylosing spondylitis and improvements with etanercept therapy. Arthritis Rheum 53: 494-501, 2005.

6. Guellec D, Nocturne G, Tatar Z, Pham T, Sellam J, Cantagrel A and Saraux A: Should non-steroidal anti-inflammatory drugs be used continuously in ankylosing spondylitis? Joint Bone Spine 81: 308-312, 2014.

7. Visser K and van der Heijde DM: Risk and management of liver toxicity during methotrexate treatment in rheumatoid and psoriatic arthritis: A systematic review of the literature. Clin Exp Rheumatol 27: 1017-1025, 2009.

8. Lateef O, Shakoor N and Balk RA: Methotrexate pulmonary toxicity. Expert Opin Drug Saf 4: 723-730, 2005.

9. Tracey D, Klareskog L, Sasso EH, Salfeld JG and Tak PP: Tumor necrosis factor antagonist mechanisms of action: A comprehensive review. Pharmacol Ther 117: 244-279, 2008.

10. Maxwell LJ, Zochling J, Boonen A, Singh JA, Veras MM, Tanjong Ghogomu E, Benkhalti Jandu M, Tugwell P and Wells GA: TNF-alpha inhibitors for ankylosing spondylitis. Cochrane Database Syst Rev 18: CD005468, 2015.

11. Sampaio-Barros PD and van der Horst-Bruinsma IE: Adverse effects of TNF inhibitors in SpA: Are they different from RA? Best Pract Res Clin Rheumatol 28: 747-763, 2014.

12. Poddubnyy D, Fedorova A, Listing J, Haibel H, Baraliakos X, Braun J and Sieper J: Physical function and spinal mobility remain stable despite radiographic spinal progression in patients with ankylosing spondylitis treated with TNF- $\alpha$ inhibitors for Up to 10 Years. J Rheumatol 43: 2142-2148, 2016.
13. Knobloch K, Yoon U and Vogt PM: Preferred reporting items for systematic reviews and meta-analyses (PRISMA) statement and publication bias. J Craniomaxillofac Surg 39: 91-92, 2011.

14. Rudwaleit M, van der Heijde D, Landewé R, Akkoc N, Brandt J, Chou CT, Dougados M, Huang F, Gu J, Kirazli Y, et al: The assessment of SpondyloArthritis international society classification criteria for peripheral spondyloarthritis and for spondyloarthritis in general. Ann Rheum Dis 70: 25-31, 2011.

15. van der Heijde D, Da Silva JC, Dougados M, Geher P, van der Horst-Bruinsma I, Juanola X, Olivieri I, Raeman F, Settas L, Sieper J, et al: Etanercept $50 \mathrm{mg}$ once weekly is as effective as $25 \mathrm{mg}$ twice weekly in patients with ankylosing spondylitis. Ann Rheum Dis 65: 1572-1577, 2006.

16. Jadad AR, Moore RA, Carroll D, Jenkinson C, Reynolds DJ, Gavaghan DJ and McQuay HJ: Assessing the quality of reports of randomized clinical trials: Is blinding necessary? Control Clin Trials 17: 1-12, 1996.

17. Higgins JP and Green S: Cochrane Handbook for Systematic Reviews of Interventions. Naunyn-Schmiedebergs Archiv für experimentelle Pathologie und Pharmakologie 5: S38, 2011.

18. Bradburn MJ, Deeks JJ, Berlin JA and Russell Localio A: Much ado about nothing: A comparison of the performance of meta-analytical methods with rare events. Stat Med 26: 53-77, 2007.

19. Wang J, Zhang Y, Zhao L, Li ZH and Shi ZJ: The efficacy and safety of infliximab used in patients with ankylosing spondylitis after unilateral total hip arthroplasty. Hip Int 23: 406-410, 2013.

20. Dougados M, van der Heijde D, Sieper J, Braun J, Maksymowych WP, Citera G, Miceli-Richard C, Wei JC, Pedersen R, Bonin R, et al: Symptomatic efficacy of etanercept and its effects on objective signs of inflammation in early nonradiographic axial spondyloarthritis: A multicenter, randomized, double-blind, placebo-controlled trial. Arthritis Rheumatol 66: 2091-2102, 2014

21. Braun J, van der Horst-Bruinsma IE, Huang F, Burgos-Vargas R, Vlahos B, Koenig AS and Freundlich B: Clinical efficacy and safety of etanercept versus sulfasalazine in patients with ankylosing spondylitis: A randomized, double-blind trial. Arthritis Rheum 63: 1543-1551, 2011.

22. Dougados M, Combe B, Braun J, Landewé R, Sibilia J, Cantagrel A, Feydy A, van der Heijde D, Leblanc V and Logeart I: A randomised, multicentre, double-blind, placebo-controlled trial of etanercept in adults with refractory heel enthesitis in spondyloarthritis: The HEEL trial. Ann Rheum Dis 69: 1430-1435, 2010.

23. Mease PJ, Kivitz AJ, Burch FX, Siegel EL, Cohen SB, Ory P, Salonen D, Rubenstein J, Sharp JT and Tsuji W: Etanercept treatment of psoriatic arthritis: Safety, efficacy, and effect on disease progression. Arthritis Rheum 50: 2264-2272, 2004.

24. Calin A, Dijkmans BA, Emery P, Hakala M, Kalden J, Leirisalo-Repo M, Mola EM, Salvarani C, Sanmartí R, Sany J, et al: Outcomes of a multicentre randomised clinical trial of etanercept to treat ankylosing spondylitis. Ann Rheum Dis 63: 1594-1600, 2004.

25. Davis JC, Van Der Heijde D, Braun J, Dougados M, Cush J, Clegg DO, Kivitz A, Fleischmann R, Inman R and Tsuji W; Enbrel Ankylosing Spondylitis Study Group: Recombinant human tumor necrosis factor receptor (etanercept) for treating ankylosing spondylitis: A randomized, controlled trial. Arthritis Rheum 48: 3230-3236, 2003.

26. Brandt J, Khariouzov A, Listing J, Haibel H, Sörensen H, Grassnickel L, Rudwaleit M, Sieper J and Braun J: Six-month results of a double-blind, placebo-controlled trial of etanercept treatment in patients with active ankylosing spondylitis. Arthritis Rheum 48: 1667-1675, 2003.

27. Gorman JD, Sack KE and Davis JC Jr: Treatment of ankylosing spondylitis by inhibition of tumor necrosis factor alpha. N Engl J Med 346: 1349-1356, 2002

28. Sieper J, Lenaerts J, Wollenhaupt J, Rudwaleit M, Mazurov VI, Myasoutova L, Park S, Song Y, Yao R, Chitkara D, et al: Efficacy and safety of infliximab plus naproxen versus naproxen alone in patients with early, active axial spondyloarthritis: Results from the double-blind, placebo-controlled INFAST study, Part 1. Ann Rheum Dis 73: 101-107, 2014.

29. Baranauskaite A, Raffayová H, Kungurov NV, Kubanova A, Venalis A, Helmle L, Srinivasan S, Nasonov E and Vastesaeger N; RESPOND investigators: Infliximab plus methotrexate is superior to methotrexate alone in the treatment of psoriatic arthritis in methotrexate-naive patients: The RESPOND study. Ann Rheum Dis 71: 541-548, 2012. 
30. Marzo-Ortega H, McGonagle D, Jarrett S, Haugeberg G Hensor E, O'connor P, Tan AL, Conaghan PG, Greenstein A and Emery P: Infliximab in combination with methotrexate in active ankylosing spondylitis: A clinical and imaging study. Ann Rheum Dis 64: 1568-1575, 2005.

31. van der Heijde D, Dijkmans B, Geusens P, Sieper J, DeWoody K, Williamson P and Braun J; Ankylosing Spondylitis Study for the Evaluation of Recombinant Infliximab Therapy Study Group: Efficacy and safety of infliximab in patients with ankylosing spondylitis: Results of a randomized, placebo-controlled trial (ASSERT). Arthritis Rheum 52: 582-591, 2005.

32. Antoni CE, Kavanaugh A, Kirkham B, Tutuncu Z, Burmester GR, Schneider U, Furst DE, Molitor J, Keystone E, Gladman D, et al: Sustained benefits of infliximab therapy for dermatologic and articular manifestations of psoriatic arthritis: Results from the infliximab multinational psoriatic arthritis controlled trial (IMPACT). Arthritis Rheum 52: 1227-1236, 2005.

33. Van Den Bosch F, Kruithof E, Baeten D, Herssens A, de Keyser F, Mielants $\mathrm{H}$ and Veys EM: Randomized double-blind comparison of chimeric monoclonal antibody to tumor necrosis factor alpha (infliximab) versus placebo in active spondylarthropathy. Arthritis Rheum 46: 755-765, 2002.

34. Braun J, Brandt J, Listing J, Zink A, Alten R, Golder W, Gromnica-Ihle E, Kellner H, Krause A, Schneider M, et al: Treatment of active ankylosing spondylitis with infliximab: A randomised controlled multicentre trial. Lancet 359: 1187-1193, 2002.

35. Huang F, Gu J, Zhu P, Bao C, Xu J, Xu H, Wu H, Wang G, Shi Q, Andhivarothai $\mathrm{N}$, et al: Efficacy and safety of adalimumab in Chinese adults with active ankylosing spondylitis: Results of a randomised, controlled trial. Ann Rheum Dis 73: 587-594, 2014.

36. Sieper J, van der Heijde D, Dougados M, Mease PJ, Maksymowych WP, Brown MA, Arora V and Pangan AL: Efficacy and safety of adalimumab in patients with non-radiographic axial spondyloarthritis: Results of a randomised placebo-controlled trial (ABILITY-1). Ann Rheum Dis 72 815-822, 2013.

37. Paramarta JE, De Rycke L, Heijda TF, Ambarus CA, Vos K, Dinant HJ, Tak PP and Baeten DL: Efficacy and safety of adalimumab for the treatment of peripheral arthritis in spondyloarthritis patients without ankylosing spondylitis or psoriatic arthritis. Ann Rheum Dis 72: 1793-1799, 2013.

38. HorneffG,FitterS,Foeldvari I,Minden K, Kuemmerle-Deschner J, Tzaribacev N, Thon A, Borte M, Ganser G, Trauzeddel R and Huppertz HI: Double-blind, placebo-controlled randomized trial with adalimumab for treatment of juvenile onset ankylosing spondylitis (JoAS): Significant short term improvement. Arthritis Res Ther 14: R230, 2012.

39. van der Heijde D, Kivitz A, Schiff MH, Sieper J, Dijkmans BA, Braun J, Dougados M, Reveille JD, Wong RL, Kupper H, et al: Efficacy and safety of adalimumab in patients with ankylosing spondylitis: Results of a multicenter, randomized, double-blind, placebo-controlled trial. Arthritis Rheum 54: 2136-2146, 2006.

40. Mease PJ, Gladman DD, Ritchlin CT, Ruderman EM, Steinfeld SD, Choy EH, Sharp JT, Ory PA, Perdok RJ and Weinberg MA; Adalimumab Effectiveness in Psoriatic Arthritis Trial Study Group: Adalimumab for the treatment of patients with moderately to severely active psoriatic arthritis: Results of a double-blind, randomized, placebo-controlled trial. Arthritis Rheum 52: 3279-3289, 2005.

41. Sieper J, van der Heijde D, Dougados M, Maksymowych WP, Scott BB, Boice JA, Berd Y, Bergman G, Curtis S, Tzontcheva A, et al: A randomized, double-blind, placebo-controlled, sixteen-week study of subcutaneous golimumab in patients with active nonradiographic axial spondyloarthritis. Arthritis Rheumatol 67: 2702-2712, 2015.
42. Mok CC, Li OC, Chan KL, Ho LY and Hui PK: Effect of golimumab and pamidronate on clinical efficacy and MRI inflammation in axial spondyloarthritis: A 48-week open randomized trial. Scand J Rheumatol 44: 480-486, 2015.

43. Sieper J, Kivitz A, van Tubergen A, Deodhar A, Coteur G, Woltering $\mathrm{F}$ and Landewé R: Impact of certolizumab pegol on patient-reported outcomes in patients with axial spondyloarthritis. Arthritis Care Res (Hoboken) 67: 1475-1480, 2015

44. Mease PJ, Fleischmann R, Deodhar AA, Wollenhaupt J, Khraishi M, Kielar D, Woltering F, Stach C, Hoepken B, Arledge T and van der Heijde D: Effect of certolizumab pegol on signs and symptoms in patients with psoriatic arthritis: 24-week results of a Phase 3 double-blind randomised placebo-controlled study (RAPID-PsA). Ann Rheum Dis 73: 48-55, 2014.

45. Landewé R, Braun J, Deodhar A, Dougados M, Maksymowych WP, Mease PJ, Reveille JD, Rudwaleit M, van der Heijde D, Stach C, et al: Efficacy of certolizumab pegol on signs and symptoms of axial spondyloarthritis including ankylosing spondylitis: 24-week results of a double-blind randomised placebo-controlled Phase 3 study. Ann Rheum Dis 73: 39-47, 2014.

46. Thalayasingam $\mathrm{N}$ and Isaacs JD: Anti-TNF therapy. Best Pract Res Clin Rheumatol 25: 549-567, 2011.

47. Taylor PC: Pharmacology of TNF blockade in rheumatoid arthritis and other chronic inflammatory diseases. Curr Opin Pharmacol 10: 308-315, 2010.

48. Kim SY and Solomon DH: Tumor necrosis factor blockade and the risk of viral infection. Nat Rev Rheumatol 6: 165-174, 2010.

49. Solomon DH, Lunt $M$ and Schneeweiss S: The risk of infection associated with tumor necrosis factor alpha antagonists: Making sense of epidemiologic evidence. Arthritis Rheum 58: 919-928, 2008.

50. Iseman MD and Fischer A: Tumor necrosis factor-alpha at the intersection of mycobacterial immunity and pathogenesis: An important new address in medicine. Clin Infect Dis 46: $1741-1742,2008$

51. Gomez-Reino JJ, Carmona L and Angel Descalzo M; Biobadaser Group: Risk of tuberculosis in patients treated with tumor necrosis factor antagonists due to incomplete prevention of reactivation of latent infection. Arthritis Rheum 57: 756-761, 2007.

52. Roos JC and Ostor AJ: Anti-tumor necrosis factor alpha therapy and the risk of JC virus infection. Arthritis Rheum 54: 381-382, 2006.

53. Fouque-Aubert A, Jette-Paulin L, Combescure C, Basch A, Tebib J and Gossec L: Serious infections in patients with ankylosing spondylitis with and without TNF blockers: A systematic review and meta-analysis of randomised placebo-controlled trials. Ann Rheum Dis 69: 1756-1761, 2010.

54. Mariette X, Gottenberg JE, Ravaud $\mathrm{P}$ and Combe B: Registries in rheumatoid arthritis and autoimmune diseases: Data from the French registries. Rheumatology (Oxford) 50: 222-229, 2011.

55. Dixon WG, Hyrich KL, Watson KD, Lunt M, Galloway J and Ustianowski A; B S R B R Control Centre Consortium, Symmons DP; BSR Biologics Register: Drug-specific risk of tuberculosis in patients with rheumatoid arthritis treated with anti-TNF therapy: Results from the British society for rheumatology biologics register (BSRBR). Ann Rheum Dis 69: 522-528, 2010.

56. Saliu OY, Sofer C, Stein DS, Schwander SK and Wallis RS: Tumor-necrosis-factor blockers: Differential effects on mycobacterial immunity. J Infect Dis 194: 486-492, 2006.

57. Wallis RS: Mathematical modeling of the cause of tuberculosis during tumor necrosis factor blockade. Arthritis Rheum 58: 947-952, 2008. 